Geochemical Journal, Vol. 1. pp. 149 to 154,1967

NOTE

\title{
Neutron activation analysis of potassium in ultrabasic rocks
}

\author{
Hiroshi Nagasawa ${ }^{1}$ and Hiroshi Wakita ${ }^{2}$ \\ Faculty of Science, Gakushuin University, Mejiro', and Radioisotope \\ School, Japan Atomic Energy Research Institute, Honkomagome, \\ Bunkyo-ku², Tokyo, Japan
}

(Received March 27, 1967)

This paper is a part of a series of the study on the abundance of radioactive elements in the 'mantle' materials. In a previous paper (WAKITA et al., 1967), we reported uranium and thorium contents of ultrabasic rocks and showed that the uranium and thorium contents and $\mathrm{Th} / \mathrm{U}$ ratio are more uniform in oceanic peridotite (1herzolite) nodules than in other classes of ultrabasic rocks. Recently, STuEber and Murthy (1966) reported potassium content of ultrabasic rocks, two of which are oceanic peridotite nodules, determined by isotope dilution method. MoRgan and GOODE (1966) also reported neutron activation analysis of potassium in one oceanic peridotite nodule from Hawaii.

Spectrometric methods, isotope dilution, $\gamma$-ray spectrometry etc., have been employed to analyze low concentration of potassium in silicate rocks. Those methods, however, may introduce a possible contamination from reagents etc. or interference by other components in the sample, when the potassium level is lower than $100 \mathrm{ppm}$.

We report here a convenient neutron activation method for the determination of potassium content lower than $100 \mathrm{ppm}$, and some results on the potassium con. tent of peridotite nodules.

The determination of potassium depends upon the measurement of $r$-activity of ${ }^{42} \mathrm{~K}$ produced by the reaction ${ }^{41} \mathrm{~K}(n, \gamma){ }^{42} \mathrm{~K}$. Abundance of ${ }^{41} \mathrm{~K}$ is $6.91 \%$ and its neutron activation cross-section is $1.0 \pm 0.2$ barns. Potassium- 42 , with a half life of $12.52 \mathrm{hr}$, decays by the emission of $\beta$ particles $(3.55,1.99 \mathrm{MeV})$ followed by the emission of $r$-photons (1.53 MeV).

About $0.5 \mathrm{~g}$ of powdered samples and the flux monitor (a piece of filter paper on which $0.2 \mathrm{mg}$ of $\mathrm{K}$ is absorbed and dried) were irradiated with a flux of $8 \times 10^{13}$ neutrons $/ \mathrm{cm}^{2} \cdot \mathrm{sec}$ for $20 \mathrm{~min}$ in the JRR 2 reactor of the Japan Atomic Energy Research Institute.

After appropriate cooling (about $24 \mathrm{hr}$ ) the samples and the flux monitor were treated by the following procedure:

(1) Fuse the irradiated samples with $2 \mathrm{~g}$ of sodium hydroxide in the presence of $\mathrm{K}$ and Cs carriers (2 mg each) and ${ }^{137} \mathrm{Cs}$-tracer (about $20,000 \mathrm{cpm}$ ), in a nickel crucible at a temperature $500-600^{\circ} \mathrm{C}$ (not above $700^{\circ} \mathrm{C}$ ) for $30 \mathrm{~min}$.

(2) Cool, add some quantity of water to wash out the fused cake, and dissolve 
in hydrochloric acid.

(3) Make the solution alkaline with sodium hydroxide, centrifuge and discard the precipitate.

(4) Make the supernatant solution acid with hydrochloric acid, add $1 \mathrm{ml}$ of ferric chloride solution $\left(5 \mathrm{mg} \mathrm{Fe} \mathrm{F}^{3+} / \mathrm{ml}\right.$ ), and repeat the ferric hydroxide scavenge.

(5) Neutralize the supernatant solution with hydrochloric acid, make the solution acid with acetic acid. Mask other metallic ions with ethylene-diamine-tetracetic acid solution. Add $3 \mathrm{ml}$ of $2 \%$ sodium tetraphenylborate solution to precipitate potassium and cesium tetraphenylborates.

(6) Centrifuge the precipitate and discard the supernatant solution.

(7) Decompose the precipitate with $30 \mathrm{ml}$ of $1 \mathrm{~N}$ nitric acid on a steam bath.

(8) Repeat the step (5).

(9) Filter the precipitate through a glass-paper filter.

(10) Dry for 5 min under an infrared lamp, and mount for the activity measurement. The radiochemical purity of the separated tetraphenylborates was examined by $r$-ray spectrometry (256-channel pulse height analyzer coupled with a scintillation detector, $2 \times 2$ in. $\mathrm{NaI}$ (Tl) crystal) and by the measurement of half life (Fig. 1). The chemical yields, determined by the recovery of ${ }^{137} \mathrm{Cs}$ were $60-70 \%$. The validity of using ${ }^{137} \mathrm{Cs}$-tracer for determining the chemical yield of potassium was checked as follows. Firstly, the possible fractionation of cesium and

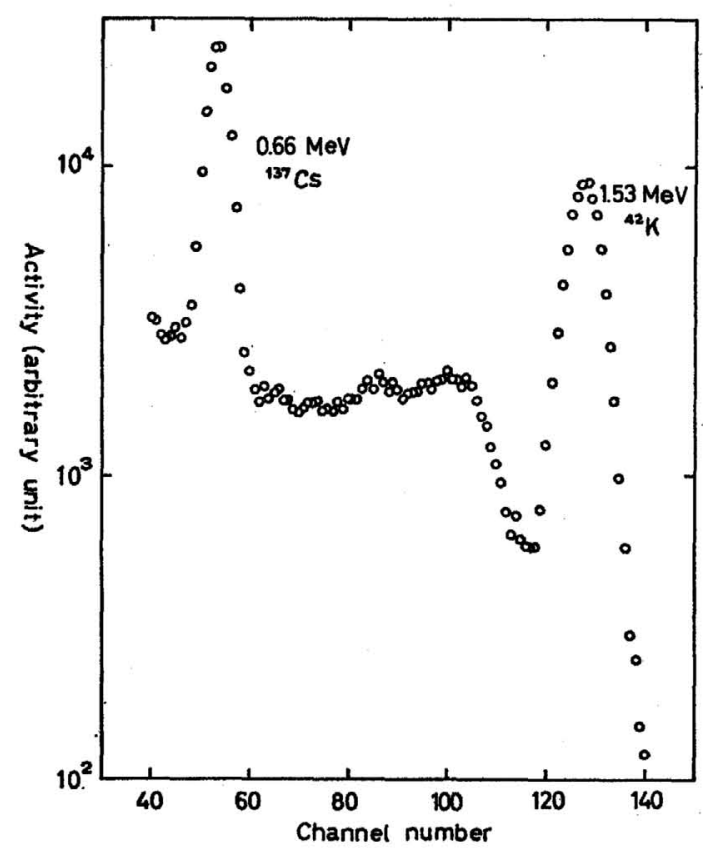

Fig. 1. $\gamma$-ray spectrum of tetraphenylborate separated from the sample 
Table 1. Test of possible fractionation of cesium and potassium during the $\mathrm{NaOH}$ fusion

\begin{tabular}{ccc}
\hline $\begin{array}{c}\text { Temperature of } \\
\text { fusion } \\
\left({ }^{\circ} \mathrm{C}\right)\end{array}$ & $\begin{array}{c}\mathrm{K} \text { and Cs recovered as } \\
\text { tetraphenylborate } \\
(\%)\end{array}$ & $\begin{array}{c}{ }^{137} \mathrm{Cs} /{ }^{\mathbf{2}} \mathrm{K} \\
(\mathrm{cpm} \text { ratio) }\end{array}$ \\
\hline without fusion & 100 & $4.88 \pm 0.08$ \\
500 & 105 & $5.00 \pm 0.09$ \\
600 & 104 & $4.95 \pm 0.08$ \\
700 & 91 & $5.05 \pm 0.09$ \\
\hline
\end{tabular}

potassium during the decomposition of the rock samples by sodium hydroxide fusion was examined by using ${ }^{137} \mathrm{Cs}$ and ${ }^{42} \mathrm{~K}$ tracers. No fractionation was observed under the experimental conditions as shown in Table 1. Secondly, the method was tested by analyzing composite samples to estimate the extent of the error arising from the whole procedure. The composite samples were prepared by diluting a basalt sample of known potassium content ( $\mathrm{K}: 1.64 \%$ ) with a sample of olivine of very low potassium content (separated from a dunite) in different proportions. It is shown in Fig. 2 that the observed values fitted well to the calculated ones.

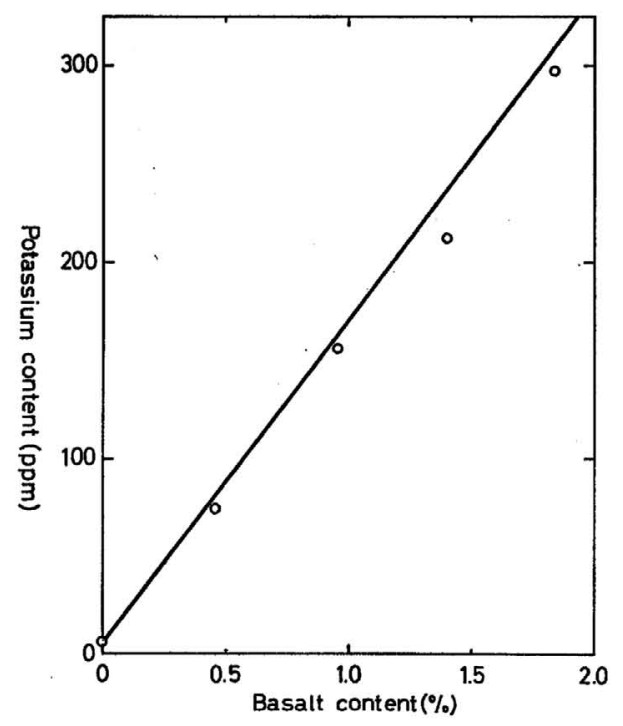

Fig. 2. $\mathrm{K}$ content $v s$, basalt content of composite samples The line is calculated from the $K$ content of the basalt ( $K: 1.64 \%$, determined by flame photometry), and $5 \mathrm{ppm}$ of $\mathrm{K}$ in olivine.

Possible interference by ${ }^{42} \mathrm{~K}$-producing nuclear reactions on other nuclides was also examined. It is shown in Table 2 that the amounts of ${ }^{12} \mathrm{~K}$ produced by the reaçtions, ${ }^{42} \mathrm{Ca}(n, p){ }^{42} \mathrm{~K}$ and ${ }^{45} \mathrm{Sc}(n, \alpha){ }^{42} \mathrm{~K}$, were too șmall to interf̣ere with the 
Table $2 .{ }^{42} \mathrm{~K}$ activity produced from ${ }^{41} \mathrm{~K},{ }^{42} \mathrm{Ca}$ and ${ }^{45} \mathrm{Sc}$

\begin{tabular}{cccc}
\hline Sample & $\begin{array}{c}\text { Weight } \\
(\mathrm{g})\end{array}$ & $\begin{array}{c}{ }^{42} \mathrm{~K} \\
(\mathrm{cpm})\end{array}$ & $\begin{array}{c}\text { Maximum error calculated } \\
\text { by assuming } \mathrm{Ca} / \mathrm{K}=10^{3}, \\
\text { and } \mathrm{Sc} / \mathrm{K}=1 \\
(\%)\end{array}$ \\
\hline $\mathrm{K}$ & $2.2 \times 10^{-1}$ & $3.1 \times 10^{1}$ & - \\
$\mathrm{Ca}$ & $8.4 \times 10^{-2}$ & $2.2 \times 10^{2}$ & 1.6 \\
$\mathrm{Sc}$ & $1.9 \times 10^{-4}$ & $5.6 \times 10^{2}$ & 1.8 \\
\hline
\end{tabular}

measurement of ${ }^{12} \mathrm{~K}$ produced from ${ }^{41} \mathrm{~K}$. From these considerations, this method of analysis can be applied to the determinations of potassium in ultrabasic rocks, allowing the total error of about 5 per cent.

Some results obtained by the present work for the peridotite nodules, together with those by other researchers, are listed in Table 3 . The uranium and thorium contents of the same samples analyzed by WAKITA et al. (1967) are also listed in the table. Values of the order of $10 \mathrm{ppm}$ were obtained for oceanic peridotite nodules, whereas Stueber and Murthy (1966) have reported 190 and 123 ppm for peridotite nodules from Kerguelen and Galapagos Isls., respectively.

It is shown in Table 3 and Fig. 3 that uniform but small values of $3 \times 10^{3}$ were obtained for $\mathrm{K} / \mathrm{U}$ ratio in these oceanic peridotite samples except the sample No. 4. These values are much smaller than that by WASSERBurg et al. (1964) who

Table 3. Concentration of radioactive elements in peridotite nodules

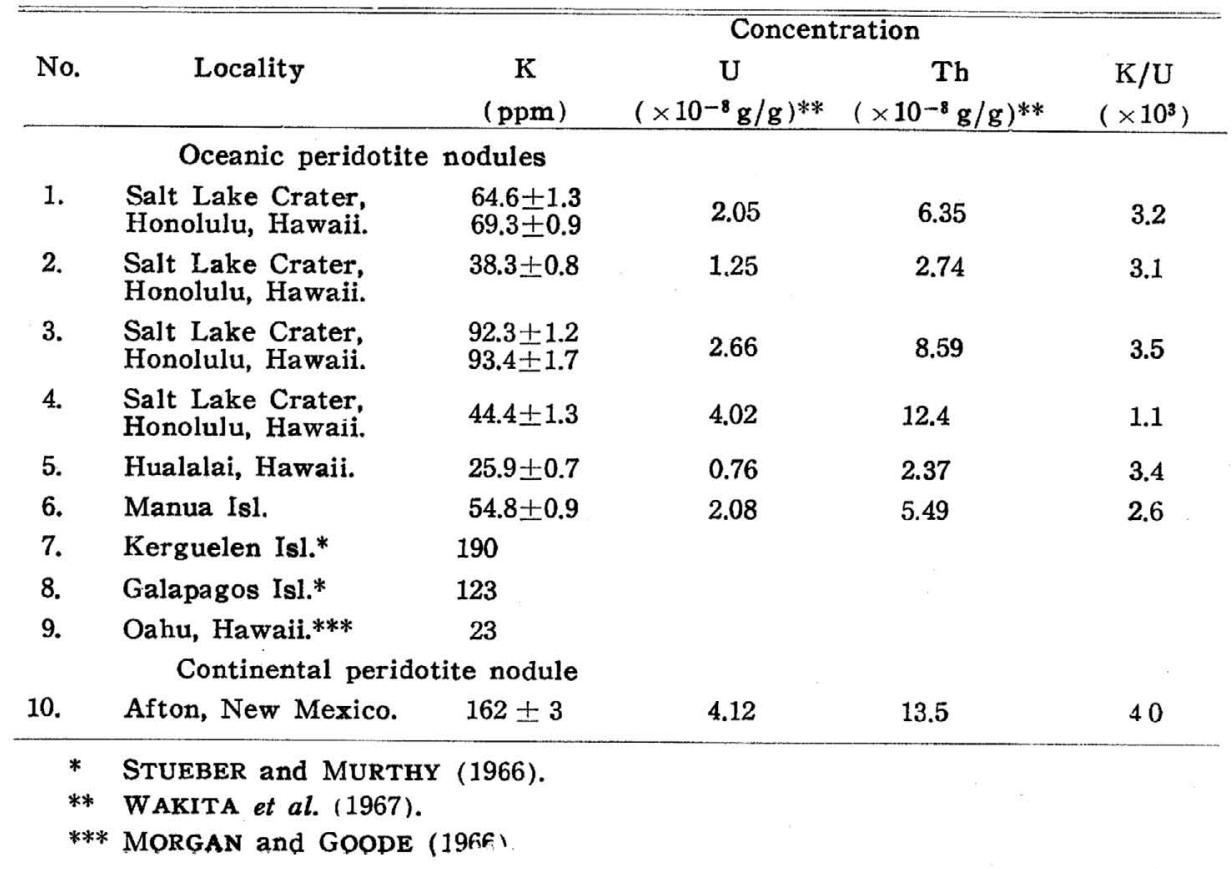




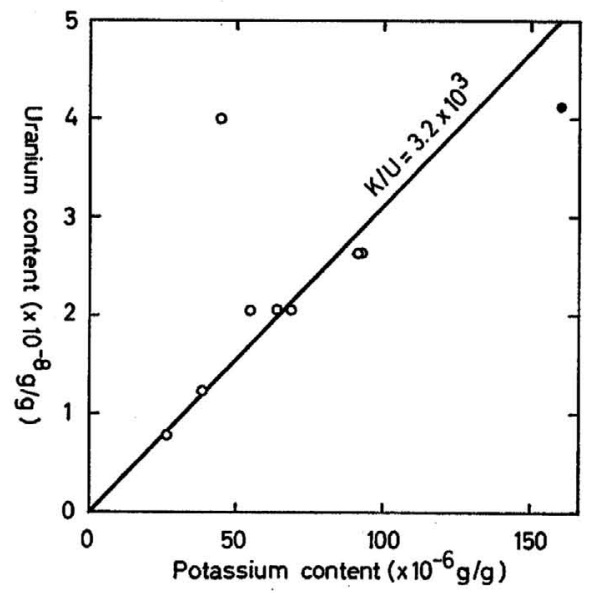

Fig. 3. $\mathrm{U}$ vs. $\mathrm{K}$ contents in peridotite nodules ०: oceanic peridotite nodules, $\bullet$ : a continental peridotite nodule

assumed $1 \times 10^{4}$ for the $\mathrm{K} / \mathrm{U}$ ratio in the mantle. These nodules would give too small heat production rates to account for the present heat flow data. From this point of view, these nodules would not represent the material of the oceanic upper mantle. The uniform $T h / U$ and $K / U$ ratios, however, suggest that the oceanic peridotites analyzed in this study would have been derived by a simple process from source materials having uniform $\mathrm{Th} / \mathrm{U}$ and $\mathrm{K} / \mathrm{U}$ ratios.

\section{SAMPle Description}

No. 1 HK 66101701

Peridotite nodule (lherzolite), Salt Lake Crater, Honolulu, Hawaii, U.S.A. Sample source: G. D. STICE et al.

No. 2 HK 66101702

Peridotite nodule (lherzolite), Salt Lake Crater, Honolulu, Hawaii, U.S.A. Sample source: G. D. Stice et al.

No. 3 HK 66101703

Peridotite nodule (lherzolite), Salt Lake Crater, Honolulu, Hawaii, U.S.A. Sample source: G. D. STice et al.

No. 4 HK $61082601 \mathrm{a}$

Peridotite nodule (lherzolite), Salt Lake Crater, Honolulu, Hawaii, U.S.A. Sample source: H. Kuno.

No. 5 HK 61030402

Peridotite nodule (1herzolite), in 1801 lava flow of Hualalai, Hawaii, U.S.A. Sample source: H. Kuno.

No. 6 Dunite nodule (lherzolite), Manua Isl., American Samoa, Sample source: 
G. D. Stice.

No. 9 HK 61081701

Peridotite nodule (lherzolite), Afton, New Mexico, U.S.A. Sample source: H.

Kuno.

\section{ACKnowledgements}

We thank Drs. Y. Murakami and H. Natsume for allowing us to use the facilities at the Japan Atomic Energy Research Institute, Dr. N. Onuma and Mr. M. NoGuchr, for the great assistance with the analytical work. Prof. H. Kuno and Dr. G. D. Stice for supplying samples for analysis. Profs. K. Kigoshi, H. Kuno and S. UYEDA are also acknowledged for discussions. This study was supported in part by the grant from Matsunaga Science Foundation.

\section{REFERENCES}

MORGAN, J. W., and Goode, A. D. T. (1966) Potassium abundances in some ultra-basic and basic rocks. Earth Planet. Sci. Letters 1, 110-112.

StUeber, A. M., and MURThy, V. R. (1966) Potassium-rubidium ratios in the ultramafic rocks: Differentiation history of the upper mantle. Science 153, 740-741; Strontium isotope and alkali element abundances in ultramafic rocks. Geochim. Cosmochim. Acta 30, 1243-1259.

WAKITA, H., NAGASAWA, H., UYEDA, S., and KUNO, H. (1967.). Uranium and thorium contents in ultrabasic rocks. Earth Planet. Sci. Letters 2, 377-381.

WAsserburg, G. J., MACDOnAld, G. J. F., Hoyle, F., and Fowler, W. A. (1964) Relative contributions of uranium, thorium, and potassium to heat production in the earth. Science 143, 465-467. 